\title{
Competitividade da produção do feijão em Goiás
}

\section{Paulo Eterno Venâncio Assunção}

Engenheiro Agrônomo, Doutorando em Economia Aplicada, Mestre em Agronegócio, professor da Faculdade de Filosofia e Ciências Humanas de Goiatuba (FAFICH).

E-mail:paulo_eterno05@hotmail.com.

\section{Alcido Elenor Wander}

Engenheiro Agrônomo, Doutor em Ciências Agrárias (Concentração: Economia Agrícola), pesquisador da Embrapa Arroz e Feijão e docente do Centro Universitário Alves Faria (UNIALFA). Bolsista de Produtividade em Pesquisa da Funadesp.

E-mail: alcido.wander@embrapa.br.

Bento Alves da Costa Filho

Administrador, Doutor em Administração, professor do Centro Universitário Alves Faria (UNIALFA) e da Fundação Getúlio Vargas (FGV).

\section{Mauro Caetano}

Doutor em Engenharia de Produção, professor da Universidade Federal de Goiás (UFG).

Resumo: O objetivo deste trabalho foi utilizar a matriz de análise de política para verificar a competitividade das três safras de feijão produzido no Estado de Goiás. Os dados produtivos foram coletados junto a produtores rurais e a agroindústria, foram considerados os custos de produção dos elos agrícolas e industrial, também foram considerados os custos de transporte e armazenagem. Os resultados mostram que a primeira e a segunda safra de feijão não são competitivas, sendo que a terceira safra apresenta um cenário um pouco melhor que as outras duas safras, mas precisa de investimentos também. Através deste estudo, pode-se notar que a não competitividade do produto se deve principalmente por parte do governo. Para a região em estudo ser competitiva não basta apenas tecnologia de ponta, ações públicas devem ser adotadas para beneficiar e dar competitividade ao produto.

Palavras chaves: Feijão, Goiás, Matriz de Análise de Política (MAP).

Abstract: We aimed to apply the policy analysis matrix in order to analyze three crops of bean produced in Goiás state, Brazil. Production data were collected from farmers and agroindustry, we considered bean production and industrial costs, and was considered the transportation and storage costs. The results show that the first and second crop of beans are not competitive, and the third harvest, a scenario a little better than the other two seasons, but needs investment too. Through this study, it can be noted that the non-competitiveness of the product is mainly by the government. To be competitive in the region is not enough to study the latest technology, public actions should be adopted to benefit and give the product competitiveness.

Key words: Bean; Goiás; Policy Analysis Matrix (PAM).

JEL Code: Q12, Q13 


\section{INTRODUÇÃO}

O presente trabalho buscou analisar a competitividade econômica das três safras de feijão produzido no Estado de Goiás, a partir da metodologia da Matriz de Análise de Política (MAP).

O feijão um produto importante na alimentação do povo brasileiro. A média atual de consumo de feijão é de 17,6 kg/brasileiro/ano (WANDER; CHAVES, 2011). A preferência do consumidor é regionalizada e diferenciada principalmente quanto à cor e ao tipo de grão. O feijoeiro comum é cultivado ao longo do ano, na maioria dos estados brasileiros, proporcionando constante oferta do produto no mercado. É cultivado tanto em culturas de subsistência quanto em cultivos altamente tecnificados. A Região Sul ocupa lugar de destaque no cenário nacional, seguida pelas Regiões Sudeste, Nordeste, Centro-Oeste e Norte.

O cultivo do feijão é feito em três safras distintas. Na primeira safra, conhecida como a safra das águas, o plantio acontece nos meses de agosto a novembro e a colheita de novembro a fevereiro. A segunda safra, chamada de safra da seca ou safrinha, ocorre no final das chuvas, tem o plantio de dezembro a março e a colheita de março a junho e a chamada terceira safra, que ocorre no inverno sendo uma safra irrigada, com plantio de abril a julho e colheita de julho a outubro (WANDER, 2007).

As regiões produtoras de feijão no Brasil vêm apresentando uma tendência em relação as suas safras. Quando observado o histórico de produção, o que se percebe é que elas vêm diminuindo a quantidade produzida na primeira e na segunda safra, principalmente na segunda safra, tendo apresentado um aumento na produção da terceira safra, que é a safra irrigada.

Com a importância apresentada pela agricultura brasileira na economia nacional, justifica-se a formulação de políticas públicas, em particular a agrícola, que atendam às necessidades especiais do setor, que reduzam o impacto negativo sobre o nível de renda da agricultura e garantam uma adequada oferta de produtos alimentares e matériaprima industrial (FAGUNDES et al., 2008; MIELITZ NETTO et al., 2010).

O trabalho está estruturado em quatro seções: esta introdução, uma seção dedicada à descrição da metodologia utilizada, uma com os resultados da pesquisa e sua discussão, e uma seção com as considerações finais do trabalho.

\section{METODOLOGIA}

O presente estudo apresenta característica de pesquisa exploratória, pois tal pesquisa permite ganhar familiaridade com o fenômeno estudado e a definir questões mais específicas que poderão ser investigadas em estudos subsequentes (SELLTIZ et al., 2004). A pesquisa foi realizada por meio de entrevista com um produtor rural da Região de Cristalina. Como preconizado na metodologia de estudo da MAP, deve-se escolher um estabelecimento rural que seja representativo para a região produtora e para a cadeia em si. Tal propriedade foi escolhida por apresentar a exploração das três safras de feijão e por apresentar os mesmos padrões em relação a cada uma das safras já apresentadas no decorrer do texto. 
Posteriormente a aplicação do questionário na propriedade rural, seguiu-se o elo de transporte da propriedade até a agroindústria processadora do feijão, também, como preconizado pela metodologia MAP, foi utilizado apenas um estabelecimento, que é uma agroindústria representativa no seguimento de industrialização do feijão e distribuição.

As entrevistas foram realizadas com a aplicação de questionários, os quais foram montados com base nas informações contidas em uma planilha de simulação eletrônica, utilizada para a comparação dos dados, fornecida pela Embrapa na publicação de Lopes et al. (2012). A coleta de dados foi feita sobre questões de identificação da propriedade, ou seja: localização, área total, tempo de existência da propriedade, investimentos, custos, entre outros.

Posteriormente, os dados foram lançados na planilha utilizando a metodologia da Matriz de Análise de Política (MAP) desenvolvida por Monke e Pearson (1989). Esta matriz possui ligações intensas com a literatura de análise de custo-benefício, com diversos exemplos de avaliação de projetos de investimento na agricultura.

A MAP, Tabela 1, utiliza dois sistemas contábeis distintos em que se consideram respectivamente os preços de mercado (ou preços privados) e os preços sociais dos diferentes insumos e produtos. Os itens levantados e que compõem as planilhas são: insumos fixos, custo do trabalho, insumos intermediários, outros custos, custo total da produção agrícola, receita com produto e subproduto, lucro antes dos impostos, impostos diretos e lucro após o imposto.

Tabela 1: Matriz de Análise de Política (MAP).

\begin{tabular}{lcccc}
\hline \multirow{2}{*}{ Item } & Receita & \multicolumn{2}{c}{ Custo } & \multirow{2}{*}{ Lucro } \\
\cline { 3 - 4 } & $\mathrm{A}$ & $\begin{array}{c}\text { Insumo } \\
\text { (transacionável) }\end{array}$ & $\begin{array}{c}\text { Recurso } \\
\text { (fator doméstico) }\end{array}$ & \\
\hline Preços privados & $\mathrm{B}$ & $\mathrm{F}$ & $\mathrm{C}$ & $\mathrm{D}$ \\
Preços sociais & $\mathrm{H}$ & $\mathrm{J}$ & $\mathrm{K}$ & $\mathrm{H}$ \\
Divergências & $\mathrm{H}$ & & $\mathrm{K}$ \\
\hline
\end{tabular}

Fonte: Monke e Pearson (1989).

Da Tabela 1 derivam as seguintes equações, conforme Monke e Pearson (1989), Alvim et al. (2004), Lucas et al. (2012) e Procópio et al. (2011):

Lucros Privados (LP):

$D=A-B-C$

Lucros Sociais (LS):

$H=E-F-G$

Transferências associadas à produção:

$I=A-E$ 
Transferências associadas ao custo dos insumos comercializáveis:

$J=B-F$

Transferências associadas ao custo dos fatores domésticos:

$K=C-G$

Transferências líquidas de Políticas:

$L=D-H$

ou

$L=I-J-K$

Lucratividade:

$D=A-B-C$

Na primeira linha da matriz, segundo Alvim et al. (2004), estão apresentados os cálculos para a valoração privada (D), onde indica os preços reais de mercado e demonstra a competitividade do sistema de produção para determinado nível tecnológico com base nos valores dos produtos, nos custos dos insumos e nas políticas de transferências (como exemplo, impostos e subsídios) prevalecentes.

A terceira identidade diz respeito às diferenças entre os valores privados e sociais de matriz, uma eventual diferença entre o preço privado observado (mercado doméstico) e o preço social estimado (eficiência) deve ser atribuído aos efeitos de políticas (na forma de taxação e subsídios) ou pela existência de falhas de mercados (SOARES et al., 2010).

Desta matriz política podem-se deduzir alguns índices, os quais auxiliam na comparação da eficiência dos diferentes sistemas de produção bem como das regiões analisadas. Inicialmente tem-se o índice de razão de custo privado $(R C P=C /(A-B))$, onde $(C)$ são os custos privados relacionados aos fatores domésticos, $(A)$ são as receitas e $(B)$ são os insumos.

Seguindo tem-se o índice de razão de custos e recursos domésticos ( $C R D=G /(E-$ $F)$ ), onde $(G)$ são custos sociais relacionados a fatores domésticos, $(E)$ demonstra as receitas medidas ao custo de oportunidade e (F)são os insumos comercializáveis.

A terceira equação diz respeito ao coeficiente de proteção nominal $C P N r=A / E$. $E$ da mesma forma este indicador pode ser aplicado aos insumos comercializáveis, resultando na seguinte equação: $C P N i=B / F$. Estes índices $C P N$ e $C P N i$ refletem o grau de proteção do produto, ou seja, proteção ou desproteção das políticas públicas, o quanto essas políticas ou falhas de mercado causam diferenças entre os preços praticados.

Já o coeficiente de proteção efetivo $(C P E=(A-B) /(E-F))$ demonstra os efeitos das medidas de políticas e falhas de mercado nos preços e nos insumos comercializáveis.

Para o coeficiente de lucratividade $(C L=(A-B-C) /(E-F-G)$ ou $C L=D / H)$ são apresentadas as seguintes equações, onde $(D)$ representa o lucro privado e $(H)$ o benefício social. 
E o último indicador, denominado razão de subsídio ao produtor $(R S P=(D-H) / E$ ou $R S P=L / E)$.

\section{RESULTADOS E DISCUSSÃO}

Na Tabela 2 são apresentados os resultados da MAP, por meios da qual foram estimados os indicadores privados e sociais da Tabela 3, 4 e 5. Para os cálculos a níveis internacionais, considerou-se a cotação oficial do Dólar Comercial do dia 31 de julho de 2013, quando foi cotado a $\mathrm{R} \$ 2,17$.

Os indicadores privados, que compõem a Tabela 2, refletem valores dos produtos e custos dos insumos a preços de mercado (privado), ou seja, representa os resultados apesar das políticas distorcidas de mercado (impostos, custo do capital, encargos sociais, etc.). Estes indicadores expressam resultados importantes para a avaliação da cadeia.

Já indicadores sociais, utilizam-se preços de paridades (ou ainda, preços internacionais equivalentes em cada nível, os border prices). O preço do produto e/ou o do insumo é convertido de dólar para real e trazido até os locais para comparação, descontando-se as despesas no processo de internalização. Os valores sociais são medidas importantes de eficiência, pois os produtos e os insumos são avaliados de maneira a refletir a escassez ou os custos de oportunidade social em atividades alternativas.

Os indicadores privados e sociais da MAP devem ser convertidos pelo modelo em uma unidade única, pois isso torna a análise mais compreensível em relação as possíveis divergências que podem ocorrer. Tal conversão deve ser passada para tonelada ou outra unidade de produto industrializado no final da cadeia. Na presente pesquisa foi obedecida a conversão em unidades de reais por hectare $(R \$ / h a)$.

Os resultados finais obtidos com o modelo analítico da MAP apresentam dois componentes. No primeiro componente são apresentados os resultados da matriz contábil da cadeia produtiva estudada, no caso a cadeia produtiva de feijão no Estado de Goiás, onde tal componente compreende as receitas e os custos privados e sociais da cadeia.

Na Tabela 2, o resultado do lucro privado é obtido através da seguinte sequência: A-B-C, onde na cadeia produtiva do feijão, foi obtido um resultado negativo de 1.131,99 para a primeira safra, 819, 09 para a segunda valor também negativo e um valor positivo de 448, 57 para a terceira safra. Em relação a primeira e segunda safra, tal valor não poderia ser negativo, sendo negativo, indica que a primeira safra de feijão no Estado de Goiás se encontra em uma difícil situação de continuidade e sobrevivência. A primeira safra de feijão deve ser desonerada de encargos decorrente de políticas públicas e ser alvo de medidas de políticas econômicas de ajustes para induzirem a uma maior rentabilidade, caso contrário o feijão produzido na primeira safra terá grandes dificuldades de continuar sendo produzido e comercializado. O que pode causar o valor negativo para o lucro privado (D) é o alto custo de produção, principalmente o gasto com insumos, que oneram o feijão de primeira safra, causando com isso um prejuízo para cadeia produtiva. 
Para a terceira safra, o resultado elevado de $D$, como o encontrado para a terceira safra de feijão, representa que a terceira safra se encontra com bons cenários de desenvolvimento dentro do Estado e que sua continuidade dentro da atividade é assegurada. O feijão de terceira safra apresenta um cenário diferente do feijão da primeira e segunda safra, pois o valor do lucro privado (D) encontrado é positivo, indicando que os custos de produção dessa safra não oneram e sim causam lucros para o lucro privado dessa safra.

Os indicadores sociais, que se referem aos preços internacionais da cadeia, a Tabela 2 mostra que o lucro social (H), obtido por E-F-G, também se encontra em estado negativo para a primeira e segunda safra. O que se pode concluir com tal valor negativo, é que a oneração dos insumos causa um lucro negativo na cadeia.

Ainda em relação ao lucro social $(\mathrm{H})$, se forem reduzidos os ônus das políticas públicas e feitos outros ajustes econômicos ou de gestão, a cadeia atrairá mais investimentos e crescerá vigorosamente. O Estado poderá incentivar por meio de políticas ou mesmo de investimentos diretos (investindo na infraestrutura, por exemplo), uma vez que os retornos sociais podem até mesmo superar os retornos privados. Muitos pesquisadores apontam o lucro social $(\mathrm{H})$ como o indicador mais importante da MAP, pois representa o que a cadeia retorna em investimentos e como está a sobrevivência da cadeia.

Com relação ao indicador H para a terceira safra de feijão, essa apresenta valor positivo para esse indicador, de 595,48. Como salientado por Lopes et al. (2012), quanto maior for o resultado do valor $\mathrm{H}$, tanto mais eficiente é a cadeia. A terceira safra de feijão, diferente das outras duas safras, apresenta cenários propícios para o investimento e crescimento de atividades.

A terceira relação contábil ou indicador obtido estabelece as divergências entre as receitas privadas e sociais (I). Tal indicador é positivo para o feijão de primeira, segunda e terceira safra. Quando tal fator é positivo, isso indica que os produtos finais da cadeia estão sendo remunerados por valores acima de seu custo social ou custo de oportunidade. O feijão produzido na primeira, segunda e terceira safra, apresentando um valor positivo para I, indica que a produção de feijão, mesmo apresentando lucro negativo pelos insumos, recebe subsídio do governo para produção e continuidade na atividade. Isso pode ser explicado pelo fato de o feijão fazer parte da cesta básica dos brasileiros, sendo necessária uma continuidade de produção para que se possa manter o mercado nacional abastecido.

A quarta relação contábil apresentada pelo método MAP estabelece a divergência para os insumos comercializáveis. Quando o valor de J é positivo, como acontece com o feijão de primeira, segunda e terceira safra, indica que os produtores estão pagando mais do que o custo social dos insumos. Quando o valor de J é positivo indica que os insumos apresentam tarifa de importação, que é um caso comum para várias cadeias produtivas, inclusive a cadeia do feijão.

A quinta relação contábil estabelece a divergência para os fatores domésticos. Um valor positivo apresentado em $\mathrm{K}$ indica que os fatores domésticos usados na cadeia em estudo (terra, capital e trabalho) estão sendo remunerados com valores acima do custo 
de oportunidade. Se o valor de $\mathrm{C}$ for maior que $\mathrm{G}$, isso resulta em um valor de $\mathrm{K}$ positivo, e se o valor de $\mathrm{K}$ for elevado, como no caso da cadeia produtiva do feijão, contando primeira, segunda e terceira safra, indica que existem distorções nos mercados dos fatores domésticos, como o caso dos encargos sociais maiores que os benefícios transferidos para os trabalhadores.

A sexta relação contábil obtido pelo método da MAP mostra o resultado líquido para a atividade econômica em estudo, no caso a cadeia produtiva do feijão de primeira, segunda e terceira safra. Tal indicador é obtido pela diferença entre $\mathrm{D}-\mathrm{H}$, ou seja, a retirada do Lucro Social (indicado pela letra $\mathrm{H}$ ) do Lucro Privado (indicado pela letra $\mathrm{D}$ ) e expresso pelo indicador representado pela letra L. Na cadeia produtiva do feijão de primeira, segunda e terceira safra o valor de L é negativo, ou seja, os Lucros Sociais esperados para a cadeia são maiores que os Lucros Privados. Isso indica que as retiradas dos impostos e de outras distorções de preços eleva o lucro privado do feijão, aproximando o indicador do lucro social.

Tabela 2: Matriz de Análise de Política para as três safras no Estado de Goiás, na safra de 2012/2013.

\begin{tabular}{ccccc}
\hline Primeira Safra & Receitas & Transacionáveis & Fatores & Lucros \\
\hline Privados & $\mathrm{A}$ & $\mathrm{B}$ & $\mathrm{C}$ & $\mathrm{D}$ \\
& $2.013,41$ & $1.995,63$ & $1.150,77$ & $1.131,99$ \\
\hline Sociais & $\mathrm{E}$ & $\mathrm{F}$ & $\mathrm{G}$ & $\mathrm{H}$ \\
& $1.857,41$ & $1.589,11$ & 451,40 & 183,09 \\
\hline Efeitos de & $\mathrm{I}$ & $\mathrm{J}$ & $\mathrm{K}$ & $\mathrm{L}$ \\
Divergência & 157,00 & 406,53 & 699,37 & 948,90 \\
\hline Segunda Safra & Receitas & Transacionáveis & Fatores & Lucros \\
\hline Privados & $\mathrm{A}$ & $\mathrm{B}$ & $\mathrm{C}$ & $\mathrm{D}$ \\
& $2.114,41$ & $2.039,09$ & 894,41 & 819,09 \\
\hline Sociais & $\mathrm{E}$ & $\mathrm{F}$ & $\mathrm{G}$ & $\mathrm{H}$ \\
& $1.857,41$ & $1.744,68$ & 391,67 & 278,93 \\
\hline Efeitos de & $\mathrm{I}$ & $\mathrm{J}$ & $\mathrm{K}$ & $\mathrm{L}$ \\
Divergência & 257,00 & 294,41 & 502,74 & 540,16 \\
\hline Terceira Safra & Receitas & Transacionáveis & Fatores & Lucros \\
\hline Privados & $\mathrm{A}$ & $\mathrm{B}$ & $\mathrm{C}$ & $\mathrm{D}$ \\
& $3.400,00$ & $2.253,81$ & 697,62 & 448,57 \\
\hline Sociais & $\mathrm{E}$ & $\mathrm{F}$ & $\mathrm{G}$ & $\mathrm{H}$ \\
& $1.859,78$ & 955,26 & 309,04 & 595,48 \\
\hline Efeitos de & $\mathrm{I}$ & $\mathrm{J}$ & $\mathrm{K}$ & $\mathrm{L}$ \\
Divergência & $1.540,22$ & $1.298,55$ & 388,57 & 148,90 \\
\hline
\end{tabular}

Fonte: Dados da pesquisa.

O custo social do capital deve ser incluído no custo dos fatores domésticos de produção. Para que se possa determinar o custo social, deve-se estimar o retorno necessário para manter o capital na atividade. No caso da primeira, segunda e terceira safra de feijão, o valor de $\mathrm{K}$ assume valor positivo. 
O valor de L negativo é esperado para qualquer cadeia estudada com o método MAP, pois as retiradas dos Lucros Sociais esperados para a cadeia em estudo devem ser maiores que os Lucros Privados, pois a retirada de impostos e de outras distorções de preços devem elevar o lucro privado da cadeia em estudo.

O valor de $\mathrm{K}$ sendo positivo, indica que a situação, que mesmo que a safra de feijão da primeira safra passe por problemas em relação ao seu lucro, ainda sim os custos dos fatores domésticos para gerar o produto, no caso o feijão, são ainda podem ser utilizados para geração de lucros, ou seja, na remuneração recebida pela mão de obra, terra e capital, sendo interessante, para os produtores, ainda se manterem na atividade. Com o valor de K positivo é possível esperar que haja novos investimentos para que possa ser aumentada e melhorada a primeira safra de feijão.

\section{INDICADORES PRIVADOS E SOCIAIS DAS TRÊS SAFRAS DE FEIJÃO}

\section{Lucro Privado}

Como pode ser observada na Tabela 3, a lucratividade privada que é expressa em termos financeiros, revela que os sistemas de produção de feijão na primeira e segunda safra, não são competitivos, isto é, $D<0$. Isso significa que os agricultores estarão desestimulados a expandir a cultura, pois o investimento na expansão dessas duas safras pode acarretar em prejuízos.

Um dos fatores que podem acarretar o lucro negativo apresentado é referente ao custo dos insumos. Estes oneram o primeiro elo da cadeia produtiva e tal custo acaba sendo repassado para todos os elos, o que causa um resultado não satisfatório como um todo em relação ao indicador. Em relação às políticas públicas voltadas para a cadeia produtiva do feijão, o Estado Goiás através de suas diretrizes poderia desenvolver parâmetros no que tange a redução dos preços dos insumos necessários à cultura do feijão.

Tabela 3: Indicadores privados e sociais da MAP na cadeia produtiva do feijão, de primeira, segunda e terceira safras, em Goiás, safra 2012/2013.

\begin{tabular}{lccc}
\hline \multicolumn{1}{c}{ Indicador } & \multicolumn{3}{c}{ (R\$/ha) } \\
\cline { 2 - 4 } & \multicolumn{4}{l}{ Lucro Privado D=A-B-C } & 1a Safra & 2a Safra & 3a Safra \\
\hline Razão do Custo Privado RCP=C/(A-B) & $(1.131,99)$ & $(819,09)$ & $(448,57)$ \\
\hline Lucro Social H=E-F-G & $(64,73)$ & $(11,87)$ & $(462)$ \\
\hline Custo de Recursos Domésticos CRD=G/(E-F) & $(183,09)$ & $(278,93)$ & $(595,48)$ \\
\hline Transferência Líquida das Políticas TLP=I-J-K & $(948,90)$ & $(5,47)$ & $(158,48)$ \\
\hline Coeficiente de Proteção Nominal CPN=A/E & $(1,08)$ & $(1,14)$ & $(1,83)$ \\
\hline Coeficiente de Proteção Efetiva CPE=(A-B)/(E-F) & $(0,06)$ & $(0,98)$ & $(1,27)$ \\
\hline Coeficiente de Lucratividade CL=D/H & $(6,18)$ & $(2,94)$ & $(0,75)$ \\
\hline Razão de Subsídio ao Produtor RSP=L/E & $(0,51)$ & $(0,29)$ & $(0,08)$ \\
\hline
\end{tabular}

Fonte: Dados da Pesquisa. 
A lucratividade privada apresentada para o feijão produzido na terceira safra, diferentemente das outras duas safras, apresenta um valor positivo, demonstrando que das safras estudadas de feijão, a terceira é a única que consegue ser competitiva no cenário nacional, apresentando um valor de $\mathrm{D}>0$. Os agricultores que concentram sua produção nessa safra estão estimulados a realizar a expansão de suas atividades, assim como o investimento em eficiência.

\section{Razão do Custo Privado (RCP)}

A Razão do Custo Privado (RCP), diferente do custo privado, esse medido em valores financeiros, o RCP é uma razão, um número relativo, que serve para indicar o grau de competitividade de cada cadeia quanto à manutenção dos fatores domésticos (terra, mão de obra e capital). A cadeia produtiva do feijão nas três safras apresenta um RCP elevado, de 64,73 para a primeira, 11,87 para a segunda e 462 para a terceira, sendo maior que a razão 1 . Ao apresentar um resultado tão elevado as safras de feijão se enquadram como não competitivas, pois os fatores de produção domésticos estão recebendo menos do que seu retorno norma.

A partir da RCP, pode-se concluir que as políticas adotadas pelo governo apresentam um gargalo e que em nenhum momento a política desenvolvida adota incentivos/benefícios em relação ao custeio de terras para as plantações, em relação à mão de obra proveniente para os produtores.

Partindo do ponto da necessidade do desenvolvimento de uma política mais eficaz neste fator, o governo precisaria conceder alguns benefícios em relação aos custos domésticos (terra, capital e trabalho). O que poderia ser feito por parte do governo seria o arrendamento de terras para plantação dos produtores, conceder determinados subsídios aos produtores na forma de isenção de encargos trabalhistas e também para suas próprias plantações. Tomando tais medidas, os custos deste fator doméstico, tenderia a cair, possibilitando aos produtores auferir ganhos e com isso beneficiar toda a cadeia produtiva, no caso a primeira safra de feijão.

Considerando apenas esse índice, a região não apresenta vocação para a produção de feijão, mas outros fatores devem ser levados em conta para ser realizada tal declaração. O valor elevado da RCP indica que as safras de feijão compartilham do problema da não eficiência das políticas em relação às ações tomadas para o início da produção em uma nova safra.

\section{Lucro Social $(\mathrm{H})$}

O indicador Lucro Social $(H)$ permite ordenar os sistemas de acordo com a eficiência ou a vantagem comparativa de um dado sistema. A primeira safra de feijão, em analise, apresentou lucro social negativo $(-183,09)$, segunda safra também apresentou valor negativo $(278,93)$, demonstrando que as duas primeiras safras de feijão não apresentam vantagem comparativa. Através desse indicador, como já discutido, entende-se que os insumos transacionáveis pesam e muito no momento de se medir o lucro social. 
Os custos, quando comparados aos fatores domésticos, demonstram certa resistência, já que eles são superiores aos custos domésticos. Observando este indicador, pode-se perceber que o quesito custo onera o resultado final, mesmo quando comparado com os níveis internacionais.

Para o lucro social $(\mathrm{H})$ a terceira safra de feijão apresentou um valor positivo de 595,48 , demonstrando que a terceira safra destoa das outras duas safras, conseguindo apresentar vantagem comparativa. Os insumos transacionáveis não oneram de maneira significativa a cadeia produtiva para a terceira safra, levando essa safra a conseguir apresentar um lucro social positivo.

\section{Custos dos Recursos Domésticos (CRD)}

Os Custo dos Recursos Domésticos (CRD) apresentado pelas três safras de feijão é maior que 1, sendo 1,68 para primeira, 3,47 para a segunda e 158,48 para a terceira safra, indicando que o valor adicionado a preços internacionais (valor do produto menos custos dos insumos transacionais) é inferior ao valor dos recursos domésticos empregados na produção, ou seja, a expansão da exploração das safras de feijão, com as atuais políticas vigentes sobre a cadeia, não traz ganhos líquidos para o país.

Em outras palavras, os preços internacionais são insuficientes para remunerar os fatores de produção domésticos. A atividade de produção do feijão na primeira safra não consegue arcar nem com os custos de produção. Enfatizando mais uma vez, os custos tornam a atividade inviável, possibilitando um resultado não satisfatório para os produtores e as políticas adotadas até o momento por parte do governo, não apresentam solução, nem ação, no quesito redução de custos, principalmente, para os fatores domésticos.

O CRD apresentado pelo feijão de primeira safra no presente estudo é de 1,68, caracterizando com isso, que os produtores utilizam $R \$ 1,68$ de recursos domésticos para economizar $\mathrm{R} \$ 1,00$ de divisa, sendo que a segunda safra utiliza 3,47 e a terceira safra 158,48 , demonstrando mais uma vez a falta de competitividade das safras de feijão. Para que esse resultado se tornasse satisfatório, as políticas agrícolas tinham que determinar pressupostos capazes de amenizar os custos de produção, seja por meio de benefícios concedidos e até mesmo a eliminação de impostos e taxas para tal indicador.

Em relação a terceira safra, a expansão dessa safra, seguindo o valor desse índice, pode não trazer nenhum ganho para o país. Embora a safra apresente cenários propícios e índices interessantes para o desenvolvimento da safra, os fatores relevantes em relação aos valores sociais aos recursos domésticos são muito maiores que os valores sociais adicionados.

Transferências Líquidas de Políticas (TLP)

O coeficiente para as transferências líquidas de políticas nas três safras de feijão em Goiás apresenta valor negativo. O que se pode concluir com tal valor negativo é que o governo, por meio das políticas públicas que interferem no preço do feijão no mercado 
e no custo dos insumos e fatores envolvidos com a produção, está transferindo recursos da cadeia para outros fatores.

As políticas adotadas pelo governo para a cadeia produtiva do feijão, nas três safras, em relação aos benefícios concedidos por políticas agrícolas demonstram ser ineficientes, sendo que o próprio governo transfere, por meio de políticas, os recursos da cadeia para outros segmentos da economia.

O governo, no Estado de Goiás, transferiu da cadeia produtiva do feijão na primeira safra $R \$ 948,90$, na segunda $R \$ 540,16$ e na terceira 148,90 por ha. Através desse indicador fica patente que as políticas públicas para a cadeia produtiva do feijão na primeira safra se enquadram como não eficazes. Isso apenas contribui para a não competitividade dessa safra e do produto.

\section{Coeficiente de Proteção Nominal (CPN)}

O Coeficiente de Proteção Nominal (CPN) para a primeira safra é de 1,08, para a segunda de 1,14 e para a terceira de 1,83, que é o resultado da relação entre a receita a preços privados e a receita a preços sociais. Como o coeficiente encontrado é maior que 1 , significa que a há proteção as safras de feijão. Tal indicar revela que o valor recebido pela cadeia correspondeu a um valor superior, a preços de mercado, ou seu valor social, ao valor que o produtor receberia na ausência de políticas causadoras de distorções.

Apesar de o índice demonstrar que existe proteção, em outras palavras, um benefício concedido pelo governo, em relação às safras de feijão, elas ainda não são competitivas, recolocando mais uma vez que as atuais políticas agrícolas implementadas pelo governo não propiciam a diminuição dos custos de produção.

\section{Coeficiente de Proteção Efetiva (CPE)}

O Coeficiente de Proteção Efetiva (CPE) é uma razão entre um valor adicionado medido a preços privados e o valor adicionado a preços mundiais. Essa razão considera os efeitos de políticas distorcidas sobre os produtos e os insumos comercializáveis. Estima, também, quanto às políticas que afetam os mercados de produtos fazem o valor adicionado diferir daquele que ocorreria na ausência de políticas para commodities. Este indicador é considerado uma medida mais completa da proteção proporcionada por políticas públicas, se comparado ao indicador de proteção nominal, que não leva em conta as políticas que incidem sobre os insumos.

No presente estudo desenvolvido sobre as safras feijão em Goiás mostra que este coeficiente é menor que 1 para a primeira e segunda safra e maior que 1 para a terceira safra, sendo 0,06 para a primeira, 0,98 para a segunda e 1,27 para a terceira.

No que tange o CPN e o CPE, ambos são chamados de indicadores de incentivos, e ambos revelam que existem políticas distorcidas em relação à primeira e segunda safra de feijão em Goiás, demonstrando que embora algumas políticas tentem proteger a cadeia produtiva de feijão, essas políticas não conseguem como todo propiciar toda a proteção em relação as fragilidades que cadeia apresenta. 
Pode-se concluir que não existe uma proteção efetiva para as duas primeiras safras, pois essa está na ordem de 0,06\% para a primeira e 0,98\%, demonstrando que as políticas adotadas são realmente ineficientes para essas safras. Este indicador considera os parâmetros em relação, principalmente, os insumos, provando que, mesmo com a pequena proteção nominal apresentada, a proteção efetiva não consegue conter os custos dos insumos que oneram de maneira muito agressiva os custos de produção.

O que se pode concluir é que se nenhuma política agrícola realmente efetiva for desenvolvida, a primeira safra de feijão está seriamente ameaçada, não conseguindo ser competitiva. As políticas devem ser desenvolvidas visando passar competitividade ao produto da primeira safra. Já para segunda safra, o indicador de 0,98 para o CPE demonstra que não existe uma proteção efetiva da cadeia, mas está perto de chegar ao indicar 1 , demonstrando que mesmo que a política adotada não apresente proteção dessa safra, está muito perto de começar a realizar essa proteção.

O CPE para a terceira safra de feijão é maior que o coeficiente 1. As políticas agrícolas adotadas conseguem proteger essa safra, apresentando eficiência nessa proteção, conseguindo propiciar toda a proteção requerida pela fragilidade da cadeia. Mesmo que a terceira safra consiga ser protegida pela proteção das políticas, é preciso que seja realizada a revisão das políticas adotadas, pois as outras safras se encontram com sérios problemas em relação a sua manutenção e expansão.

\section{Coeficiente de Lucratividade $(C L)$}

O Coeficiente de Lucratividade (CL) é a razão entre o lucro privado e o lucro social. Tal razão apresenta o cenário de como seria a distância entre o lucro privado e o lucro social que se poderia obter na ausência de políticas causadoras de distorções. O CL apresentado pela primeira safra de feijão é de 6,18, o da segunda é de 2,94 e a terceira 0,75 .

O CL indica que a primeira e a segunda safra estão sendo liquidamente subsidiadas. Apesar de não ser um indicador completo de incentivos, pode-se concluir que os subsídios aplicados neste caso e que se refletem nos cálculos não se traduzem em competitividade para essa safra.

As políticas atuais deixam muito a desejar em relação a sua eficiência com a primeira e a segunda safra de feijão. Mesmo com os incentivos e serviços apresentados pelo governo através de algumas políticas agrícolas para o Estado, o feijão de primeira e segunda safra não conseguem adquirir competitividade. Isso pode ser relacionado a problemas de cunho das próprias políticas, que não se traduzem com profundidade na resolução dos problemas da primeira safra de feijão.

O CL apresentado para a feijão de terceira safra foi diferente do apresentado pelas outras duas safras, pois o valor foi menor que o índice 1 . O valor encontrado para a terceira safra foi de 0,75 , o que representa uma grande distorção, pois isso indica que houve desproteção a atividade da terceira safra, ou seja, a produção de feijão de terceira safra está sendo liquidamente taxada. A terceira safra está sofrendo taxações de produtos, demonstrando grande desacordo com o coeficiente encontrado para as outras 
safras, isso indica que as distorções políticas encontradas no presente estudo causam a chamada bizarrice (LOPES et al., 2012) e taxa de maneira onerosa à única das três safras que apresentam condições de crescimento lucrativo para os produtores.

\section{Razão de Subsídio ao Produtor (RSP)}

A Razão de Subsídio ao Produtor (RSP) é a transferência líquida de política como proporção da receita social total. Esse indicador permite comparar a extensão e em que as políticas subsidiam os sistemas e pode ser desagregada para mostrar os efeitos de políticas de produtos, insumos e fatores.

Um índice tão elevado encontrado para a RSP de feijão na primeira safra demonstra os riscos encontradas por essa safra, pois o índice negativo tão elevado, representa que essa safra de feijão apresenta redução de $50 \%$ em sua rentabilidade devido a desproteção encontrada pelos produtores. A RSP da cadeia produtiva do feijão de segunda safra também apresentou valor negativo $(0,29)$. Tal fator indica que desproteção encontrada pelos produtores gera uma redução na rentabilidade em torno de $30 \%$. O resultado encontrado para essas safras indica que elas foram taxadas. Isso quer dizer que mesmo o governo concedendo benefícios através de políticas agrícolas, o próprio governo realiza a taxação abusiva em cima das safras, não contribuindo para a competitividade.

A RSP da terceira safra foi menor, apresentando um valor negativo de 0,08. Esse valor indica que essa desproteção encontrada pelos produtores provoca redução na rentabilidade em torno de $10 \%$.

\section{CONSIDERAÇÕES FINAIS}

Por ser uma atividade de grande importância econômica, social, e também cultura para as regiões de produção tradicionais, para o Estado de Goiás, mas apresentando características diferentes em relação as suas safras, a produção de feijão requer uma política de desenvolvimento sustentável, que contemple desde o pequeno produtor, com pouco emprego de tecnologia em seus processos produtivos, ao grande produtor, que emprega tecnologia e produção em larga escala.

Uma das maneiras de melhorar a competitividade do feijão produzido dentro do Estado de Goiás seria o desenvolvimento de políticas públicas que exercessem condições de estabelecimento da competitividade da cultura. O que poderia ser feito seriam acordos entre os produtores e indústrias, com seus respectivos representantes, para garantir uma melhor remuneração para o feijão produzido e comercializado, podendo tomar por base de preço de mercado, referentes a cotações que estejam atreladas ao custo de produção da região, visando o pagamento de um valor mais justo ao produtor em relação ao seu custo de produção.

A região precisa seriamente de recursos, tanto públicos como privados para alcançar um nível que possa tornar a cadeia como um todo. Esta competitividade precisa 
englobar políticas públicas rígidas que façam do grão produzido no Estado um produto com capacidade de competir de frente com o grão produzido em outros Estados.

Um dado alarmante se refere a razão de subsídio ao produtor. Esse dado mede a proteção apresentada por parte das políticas em relação aos produtores. Os dados encontrados demonstram que as safras de feijão estão em situação de desproteção. A redução da rentabilidade na primeira safra é de em torno de 50\%, na segunda safra de $30 \%$ e na terceira, que apresenta o menor índice, é de $10 \%$. Ações visando à melhoria das políticas precisam ser adotas para que a atividade não fique desprotegida e os produtores possam gozar de uma atividade rentável.

O que fica claro em relação à cadeia produtiva de feijão é que a não competitividade do produto no Estado de Goiás começa através de partes governamentais, isto é, o próprio governo, mais precisamente as entidades que cuidam das políticas agrícolas, não concedem uma ajuda digna aos produtores, consequentemente, não favorecendo uma base para a comercialização do produto. Enfim, através deste estudo, pode-se notar que o nível de competitividade do produto no Estado é muito aquém do esperado.

Para novos estudos recomenda-se a utilização de avaliações de políticas públicas em relação aos incentivos ao desenvolvimento da cadeia produtiva do feijão, assim como estudos que busquem analisar a formação dos sistemas agroindustriais para processamento do produto e estudos que visem compreender como ocorre a friç̧ão dentro da cadeia pela passagem do produto (Custos de Transação).

\section{REFERÊNCIAS}

ALVIM, M.I. da S.A.; VALLE, S.M.L.R. do; LIMA, J.E.; SILVA, O.M. da. Análise da competitividade da produção de soja nos sistemas de plantio direto e plantio convencional na região do cerrado brasileiro. Revista de Economia e Sociologia Rural, Brasília, v.42, n.2, p.223-242, abr./jun. 2004.

FAGUNDES, M.B.B.; LIMA FILHO, D.O.; TREDEZINI, C.A.O.; SILVA, M.G.E.; SANTOS JÚNIOR, J.R.; SIMÕES, A.R.P. Análise da competitividade da cotonicultura no Estado de Mato Grosso do Sul: aplicação da Matriz de Análise de Política (MAP). Revista de Economia e Administração, Campo Grande, v.9, n.18, p.5-20, mai./ago. 2008.

LOPES, M.R.; OLIVEIRA, A.J.; TORRES, D.A.P.; TALAMINI, D.J.D.; MARTINS, F.M.; LIMA FILHO, J.R.; BELARMINO, L.C. Matriz de Análise de Política: metodologia e análise. Brasília, DF: Embrapa, 2012.

LUCAS, L.S.; BRUMATI, R.C.; ALENCAR, S.A.S.; PINI, T.R.M. Comparação da eficiência de sistemas produtivos em bovinos de corte utilizando a Matriz de Análise de Política (MAP). Informações Econômicas, São Paulo, v.42, n.6, p.54-64, 2012.

MIELITZ NETTO, C.G.A.; MELO, L.M.; MAIA, C.M. Políticas públicas de desenvolvimento rural no Brasil. Porto Alegre: Editora da UFRGS, 2010.

MONKE, E.; PEARSON, S.R. The policy analysis matrix for agricultural development. Ithaca: Cornell University Press, 1989. 
PROCÓPIO, D.P.; JESUS, R.B.; LEITE, C.A.M. Análise comparativa da indústria canavieira dos Estados do Paraná e do São Paulo. Revista de Política Agrícola, Brasília, DF, v.20, n.1, p.66-78, jan./mar. 2011.

SELLTIZ, C.; WRIGHTSMAN, L. S.; COOK, S. W. Métodos de pesquisa nas relações sociais. São Paulo: Epu, 2004.

SOARES, N.S; SILVA, M.L.; REZENDE, J.L.P.; GOMES, M.F.M Competitividade da cadeia produtiva da madeira de eucalipto no Brasil. Revista Árvore, Viçosa, v.34, n.5, p.917-928, 2010.

WANDER, A.E. Produção e consumo de feijão no Brasil, 1975 - 2005. Informações Econômicas, São Paulo, v.37, n.2, p.7-21, 2007.

WANDER, A.E.; CHAVES, M. O Consumo per capita de feijão no Brasil de 1998 a 2010: uma comparação entre consumo aparente e consumo domiciliar. In: 10 Congresso Nacional de Pesquisa de Feijão (CONAFE), Goiânia, GO. Anais... Goiânia, GO: Embrapa Arroz e Feijão, CD-ROM, 2011, 4p. 
p. 35 - Competitividade da produção do feijão em Goiás

Anexo - Questionário utilizado

QUESTIONÁRIO INICIAL PARA AS ENTRADAS NA MATRIZ DE ANÁLISE DE POLÍTICA (MAP).

Titulo da pesquisa: Análise da Competitividade da Cadeia Produtiva do Feijão-Comum: Um estudo de caso utilizando a Matriz de Análise de Política (MAP).

Instituição: Universidade Federal de Goiás/Embrapa Arroz e Feijão.

Responsável pela pesquisa: Mestrando Paulo Eterno Venâncio Assunção

Orientador: Dr. Alcido Elenor Wander

* O responsável pela pesquisa garante total anonimato das informações apresentadas pelos entrevistados, sendo o uso dessas para fins de pesquisa científica e entendimento do funcionamento da cadeia produtiva estudada, as informações relacionadas à identificação dos entrevistados são meramente para controle da pesquisa, não serão divulgados nessa pesquisa os nomes, empresas ou organizações dos entrevistados exceto caso solicitado pelo entrevistado.

DADOS DO ENTREVISTADO:

\begin{tabular}{|l|l|}
\hline Nome Completo & \\
\hline Empresa/Organização & \\
\hline Cargo & \\
\hline Cidade & \\
\hline Contato & \\
\hline
\end{tabular}

QUESTÕES:

1) Descreva o funcionamento do seu processo produtivo e em qual safra se concentra sua produção (1a $2^{\text {a }}$ ou $3^{\text {a }}$ safra)?

Resposta

2) Qual o volume de produção de feijão na respectiva safra?

Resposta

3) Quais os tipos de feijão que vocês trabalham e por que da escolha desse produto? Resposta 
Paulo E. V. Assunção; Alcido E. Wander; Bento A. da Costa Filho e Mauro Caetano - p.36

4) Quais os principais impostos que incidem sobre o processo produtivo e comercialização?

Resposta

5) Quais os principais incentivos fiscais recebidos pela cadeia?

Resposta

6) No processo de compra, existem incentivos (financiamentos, ajudas de custos etc) nessa aquisição?

Resposta

7) No processo de compra, os preços pagos são em cotação de Dólar ou Real?

Resposta

8) Qual custos pesa mais na produção: os custos variáveis ou custos fixos?

Resposta

9) Vocês realizam o controle contábil de todo o processo produtivo?

Resposta

10) Os preços cobrados dentro do processo produtivo são cotados em Dólar ou em Real? Resposta

Tabela como entrada inicial para análise da Matriz de Análise de Política

\section{CUSTOS PRIVADOS}

Data do estudo:

Unidade monetária do estudo:

Unidade de área:

10 elo: do plantio a colheita

Produto básico 
p. 37 - Competitividade da produção do feijão em Goiás

Descrição da cadeia:

Rendimento:

Peso do saco em kg:

Unidade de medida dos cálculos (tonelada):

I - cálculo dos custos fixos por meio do uso do fator de recuperação do capital

\begin{tabular}{|l|l|l|l|l|l|l|}
\hline $\begin{array}{l}\text { Insumos } \\
\text { fixos }\end{array}$ & $\begin{array}{l}\text { Taxa de } \\
\text { retorno } \\
\text { (em } \\
\text { decimal) }\end{array}$ & $\begin{array}{l}\text { Custo } \\
\text { inicial }\end{array}$ & $\begin{array}{l}\text { Valor } \\
\text { residual }\end{array}$ & $\begin{array}{l}\text { Vida útil } \\
\text { (anos) }\end{array}$ & $\begin{array}{l}\text { Participação } \\
\text { (uso anual } \\
\text { em decimal) }\end{array}$ & $\begin{array}{l}\text { Custo do } \\
\text { capital }\end{array}$ \\
\hline Entradas & & & & & & \\
\hline Subtotal I & & & & & & \\
\hline
\end{tabular}

II - Custo do trabalho

\begin{tabular}{|l|l|l|l|}
\hline Descrição & Não qualificado & Qualificado & Total \\
\hline $\begin{array}{l}\text { Trabalhos } \\
\text { realizados }\end{array}$ & & & \\
\hline Subtotal II & & & \\
\hline
\end{tabular}

III - insumos intermediários

\begin{tabular}{|l|l|l|l|l|l|}
\hline \multicolumn{2}{|l|}{$\begin{array}{l}\text { Descrição/Nome } \\
\text { comercial }\end{array}$} & Unidade & Quantidade & Preço/Unidade & Valor total \\
\hline Insumos & & & & & \\
\hline Subtotal III & & & & & \\
\hline
\end{tabular}

Lucro antes dos impostos: total das receitas - custos total = lucro

Impostos diretos: entradas incidentes a produção.

Lucro após os impostos: Lucro - Impostos diretos = lucro sem impostos. 